\title{
¿Qué hacer en caso de ...? Decisiones oncológicas durante cirugía
}

\author{
What to do in case of...? Oncological decisions during surgery
}

\author{
Mauricio García-Mora' ${ }^{\mathbb{D}}$, Gilbert F. Mateus-López² $\mathbb{D}$
}

1 Médico, especialista en Cirugía general y Cirugía Oncológica; coordinador, Programa de Cirugía Oncológica, Instituto Nacional de Cancerología, Bogotá, D.C, Colombia

2 Médico, especialista en Cirugía general y Cirugía Oncológica, Fundación Valle del Lili; director, Especialización en Cirugía Oncológica, Pontificia Universidad Javeriana, Cali, Colombia

En cifras generales, la incidencia de cáncer en el mundo viene en aumento y el perfil de las diferentes presentaciones va cambiando dadas las características propias de tipo geográfico, genético, de exposición, hábitos y costumbres, entre países e incluso dentro de un mismo país. El acceso a las instituciones de salud y el desarrollo de la tecnología incrementan el poder de diagnóstico, tanto específico como el incidental, en programas de tamización, en pacientes con sospecha de neoplasia o en algunos que asisten por causas diferentes, en busca de atención programada o de urgencias.

Está demostrado que el mayor impacto en la mortalidad se logra con los programas de prevención y gestión del riesgo. Reflejo de ello es la disminución en la incidencia de cáncer de pulmón o de cérvix, con relación a la regulación del consumo de tabaco y los programas de vacunación masiva contra el virus del papiloma humano. Si- tuación similar ocurre con el hepatocarcinoma asociado a hepatitis B crónica, lo que impacta de manera frontal en la incidencia y la mortalidad derivada de ella.

Sin embargo, en la mayor parte de las patologías malignas no se ha podido actuar en la prevención. Es aquí donde el diagnóstico temprano se vuelve pieza fundamental para disminuir la mortalidad, de la mano con los tratamientos oportunos, adecuados y eficientes, que cuenten con talento humano calificado, así como con condiciones físicas y tecnológicas apropiadas.

Colombia no es ajena a esta dinámica. Las patologías oncológicas de mayor frecuencia requieren en alguna parte del proceso de atención de la participación de un especialista quirúrgico, bien sea dentro del proceso diagnóstico, en el tratamiento específico o la paliación, contemplado y reglamentado según la normatividad vigente para la atención del cáncer en el país.

Palabras clave: cirugía general; oncología quirúrgica; neoplasias; hallazgos incidentales; urgencias médicas.

Keywords: general surgery; surgical oncology; neoplasms; incidental findings; medical emergencies.

Fecha de recibido: 3/10/2021 - Fecha de aceptación: 18/10/2021 - Publicación en línea: 29/10/2021

Correspondencia: Gilbert F. Mateus-López, Calle 2 \# 130 - 65 Casa 2, Reserva del Rio, Cali, Colombia. Teléfono: 3183366592

Dirección electrónica: gfmateusib@yahoo.com

Citar como: Garcia-Mora M, Mateus-Lopez GF. ¿Qué hacer en caso de ...? Decisiones oncológicas durante cirugía. Rev Colomb Cir. 2022;37:19-20. https://doi.org/10.30944/20117582.1871

Este es un artículo de acceso abierto bajo una Licencia Creative Commons - BY-NC-ND https://creativecommons.org/licenses/by-nc-nd/4.0/deed.es 
La formación de cirujanos especializados en cáncer es vital para un modelo de atención ideal, pero en la realidad actual, la cantidad de subespecialistas y su distribución en las diferentes regiones del país, con lugares habilitados para ejercer la oncología de manera integral, no es apropiada. Esto lleva al cirujano general a tener el primer encuentro con los pacientes de patología oncológica, para tomar conductas, principalmente en el contexto de la urgencia, situación que se complica en ocasiones ante las dificultades para la remisión o traslado de un paciente dentro del sistema de salud.

Tomar la decisión inicial adecuada influye de manera importante en el proceso de atención y en el tratamiento específico de los pacientes, incluso en su pronóstico.

El liderazgo y la visión integral tienen un papel importante dentro del perfil del cirujano oncólogo moderno. La sensibilización, el entendimiento y el apoyo en la educación de los participantes en los procesos de atención de los pacientes con cáncer es fundamental en el objetivo de su ejercicio. Si entendemos que cada uno de nosotros hace parte del engranaje de la atención, y que cada aporte es valioso y definitivo en la oportunidad, eficiencia y calidad, estaremos poniendo un grano de arena para disminuir la brecha tortuosa que recorre el paciente con cáncer por el fraccionamiento de su proceso diagnóstico y terapéutico.

Este espacio que abre la Revista Colombiana de Cirugía nos permitirá presentar un ejercicio académico de parte cirujanos generales en formación durante su especialización en cirugía oncológica y refleja justamente la intención de aportar y apoyar en las decisiones a quienes ejercen día y noche su labor de primera línea con compromiso y responsabilidad.

La primera entrega es una serie de revisiones enfocadas en situaciones para la toma de decisiones, frente a hallazgos oncológicos incidentales en pacientes con otras patologías quirúrgicas de urgencia habituales para el cirujano general. Se hace una revisión sistemática de la literatura y se construye un algoritmo de conductas basadas en la evidencia y ajustadas a la realidad del ejercicio.

Esperamos que sea una herramienta valiosa para el cirujano general, para los colegas en formación en todos los niveles y para los grupos de atención en salud, pretendiendo dar una guía para la respuesta a ¿qué hacer en caso de ...? 